\title{
Pulmonary nocardiosis in an elderly man
}

\author{
Nitin Gupta, ${ }^{1,2}$ Muralidhar Varma, ${ }^{1}$ Shubha Sheshadri, ${ }^{3}$ Kavitha Saravu ${ }^{1,2}$
}

${ }^{1}$ Department of Infectious Diseases, Kasturba Medical College Manipal, Manipal, Karnataka, India

${ }^{2}$ Manipal Center for Infectious Diseases, Prasanna School of Public Health, Manipal, Karnataka, India ${ }^{3}$ Department of Medicine, Kasturba Medical College Manipal, Manipal, Karnataka, India

\section{Correspondence to}

Dr Kavitha Saravu;

kavithasaravu@gmail.com

Accepted 11 January 2020

Check for updates

(C) BMJ Publishing Group Limited 2020. No commercial re-use. See rights and permissions. Published by BMJ.

To cite: Gupta N, Varma M, Sheshadri $S_{\text {, et al. BMJ Case }}$ Rep 2020;13:e234090. doi:10.1136/bcr-2019234090

\section{DESCRIPTION}

A 72- year-old farmer from South India presented to our emergency room with chief complaints of fever for 25 days, cough with expectoration for 10 days and respiratory distress for 2 days. He was apparently asymptomatic 25 days back when he developed intermittent high-grade fever with evening rise of temperature. This was associated with significant loss of appetite and loss of weight. For these complaints, he visited a local practitioner who prescribed him some antibiotics for 5 days (details not available). There was some relief in fever with the antibiotics, but his symptoms recurred after a gap of 4 days. Ten days prior to the presentation, he started to have insidious-onset progressive cough with copious sputum expectoration. He presented to our emergency with 2 days of acutely progressive dyspnoea. He did not have any history of tuberculosis. There was no significant history of contact/ exposure or high-risk behaviour. He was a 'previous smoker' (50 pack-years) and a recently diagnosed diabetic (Glycosylated haemoglobin-7.2\%). On admission, his breaths sounds were significantly reduced in the right upper, middle and lower zones. Routine haematological and biochemical parameters were normal expect for leucocytosis (total leucocyte count $-14.2 \times 10^{9} / \mathrm{L}$, differential count-neutrophil-94\%, lymphocyte-2\%, monocyte-2\%, eosinophil-1\%, basophil-1\%). $\mathrm{He}$ was intubated in view of severe hypoxaemia (partial pressure of oxygen on room air- $41 \mathrm{~mm}$ of mercury, periphery capillary oxygen saturation on room air-80\%). His chest X-ray showed diffuse heterogeneous opacities in right upper zone and bilateral middle and lower zones (figure 1A). The patient was empirically initiated on piperacillin-tazobactam and azithromycin according to the hospital antibiotic policy. Antibodies against HIV 1 and 2 were negative. GeneXpert for Mycobacterium tuberculosis complex (MTBC) from endotracheal aspirate was negative. Gram stain of the endotracheal aspirate showed gram positive filamentous branching bacilli, which was acid fast on Kinyoun's staining. The empiric antibiotics were modified to imipenem and cotrimoxazole with a suspicion of nocardiosis. The aerobic culture of endotracheal aspirate on blood agar was found to be positive for Nocardia spp. The identification could only be done up to genus level by matrixassisted laser desorption ionisation time of flight mass spectrometry. MRI of the brain was done to look for cerebral nocardiosis which was normal. The patient was started on imipenem and linezolid based on the preliminary results of susceptibility testing (disc diffusion). The patient's general condition gradually improved. Imipenem was stopped after the patient was weaned-off ventilator (day 25

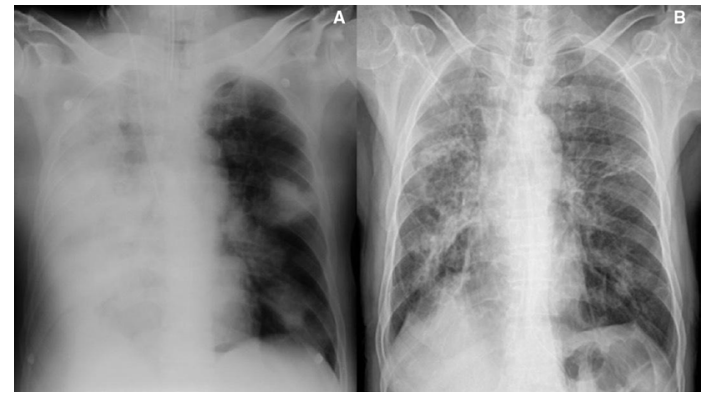

Figure 1 (A) Chest X-ray at the time of admission showing extensive consolidation in the right haemithorax and patchy opacities in the left haemithorax; (B) chest $\mathrm{X}$-ray at the time of discharge showing significant resolution.

of admission). He was continued on oral linezolid and oral minocycline was added considering the extensive pulmonary involvement. A repeat X-ray was done at the time of discharge, which showed significant radiological resolution (figure 1B). The patient was discharged after he had received a total of 41 days of appropriate antibiotics for nocardiosis. He was planned to receive 6 months of oral minocycline and linezolid.

Nocardiosis is usually seen in elderly individuals or immunosuppressed patients (transplantation, glucocorticoid therapy, HIV, diabetes mellitus). In a series of 40 patients with nocardiosis, diabetes $(32.5 \%)$ was found to be the most common risk factor. ${ }^{1}$ Lung involvement is the most common manifestation of nocardiosis. Patients with pulmonary nocardiosis usually present with acute, subacute or chronic onset of cough and haemoptysis with constitutional symptoms. ${ }^{2}$ On the X-ray, air space disease is the most common radiological abnormality with an upper lobe predilection. Other common radiological abnormalities are nodules, mass, cavities or effusion. The radiological abnormalities may range from mild to extensive. Extensive air space opacification similar to our case has been described in other cases series as well. ${ }^{3}$ The differentials of nocardiosis include tuberculosis, fungal infections and malignancy. ${ }^{2}$ Like MTBC, it

\section{Patient's perspective}

My father was actively working in farms before he got sick. We were very scared as we were informed that his lung conditions are very bad and there is an infection with a rare organism. He remained on ventilator for about a month. I am happy that he has regained his strength and is now able to do his daily activities by himself. 


\section{Learning points}

- Nocardiosis should be suspected in elderly patients or patients with diabetes who present with chronic respiratory symptoms not responding to antibiotics.

- It is a close differential of tuberculosis in terms of clinical presentation (chronic productive cough with constitutional symptoms and upper lobe involvement) and microbiological characteristics (acid fastness).

is acid fast (using modified acid-fast staining) but may not grow after the decontamination procedures used for MTBC diagnostics is employed. Also, growth of Nocardia spp on culture may require prolonged incubation up to 3 weeks. Therefore, laboratory should be communicated about the suspicion of nocardiosis. ${ }^{4}$ Patients with severe pulmonary nocardiosis are usually treated initially with a two-drug combination intravenous therapy containing imipenem, cotrimoxazole, linezolid or amikacin depending on the susceptibility. The combination intravenous therapy is usually switched to oral therapy after 3-6 weeks. Oral therapy may be continued for 6-12 months. ${ }^{5}$

Contributors NG and KS contributed in the conception, case management and the drafting of manuscript. MV and SS contributed in case management and revision of the manuscript. KS was responsible for overall supervision.

Funding The authors have not declared a specific grant for this research from any funding agency in the public, commercial or not-for-profit sectors.

Competing interests None declared.

Patient consent for publication Obtained.

Provenance and peer review Not commissioned; externally peer reviewed.

\section{REFERENCES}

1 Yang $M, X u M$, Wei W, et al. Clinical findings of 40 patients with nocardiosis: a retrospective analysis in a tertiary hospital. Exp Ther Med 2014;8:25-30.

2 Zia K, Nafees T, Faizan M, et al. Ten year review of pulmonary nocardiosis: a series of 55 cases. Cureus 2019;11:e4759.

3 Aggarwal D, Garg K, Chander J, et al. Pulmonary nocardiosis revisited: a case series. Lung India 2015;32:165-8.

4 Fatahi-Bafghi M. Nocardiosis from 1888 to 2017. Microb Pathog 2018;114:369-84.

5 Wilson JW. Nocardiosis: updates and clinical overview. Mayo Clin Proc 2012;87:403-7.

Copyright 2020 BMJ Publishing Group. All rights reserved. For permission to reuse any of this content visit

https://www.bmj.com/company/products-services/rights-and-licensing/permissions/

BMJ Case Report Fellows may re-use this article for personal use and teaching without any further permission.

Become a Fellow of BMJ Case Reports today and you can:

- Submit as many cases as you like

- Enjoy fast sympathetic peer review and rapid publication of accepted articles

- Access all the published articles

- Re-use any of the published material for personal use and teaching without further permission

Customer Service

If you have any further queries about your subscription, please contact our customer services team on +44 (0) 2071111105 or via email at support@bmj.com.

Visit casereports.bmj.com for more articles like this and to become a Fellow 